The impact of commitment on nonrenewable resources management with asymmetric information on costs

Julie Ing 


\section{GATE Groupe d'Analyse et de Théorie Économique Lyon-St Étienne}

93, chemin des Mouilles 69130 Ecully - France

Tel. +33(0)4 72866060

Fax $+33(0) 472866090$

6, rue Basse des Rives 42023 Saint-Etienne cedex 02 - France

Tel. +33 (0)4 77421960

Fax. +33 (0)4 77421950

Messagerie électronique / Email : gate@gate.cnrs.fr

Téléchargement / Download : http://www.gate.cnrs.fr - Publications / Working Papers 


\title{
The impact of commitment on nonrenewable resources management with asymmetric information on costs
}

\author{
Julie ING*
}

April 12, 2012

\begin{abstract}
We study the optimal contracts (payment and extraction path) implemented by a regulator unable to commit to long term contracts that delegates the extraction of a nonrenewable resource to a firm. The regulator wishes to maximize the tax revenue and does not know the firm's efficiency which is private information. As the regulator is unable to commit, the ratchet effect appears. We show that the contracts implemented depend on which types of firms exhaust the stock. If both types exhaust the stock, the contracts are fully separating and similar to those implemented under full commitment. The

*Université de Lyon, Lyon, F-69007, France ; CNRS, GATE Lyon Saint-Etienne, Ecully, F-69130, France. Tel. +33 (0)4 72866114 Fax +33 (0)4 72866090 Email:
\end{abstract} ing@gate.cnrs.fr 
efficient firm produces the first best and gets an informational rent whereas the inefficient one produces lower quantity. If the stock is not exhausted, the contracts are semi separating and the inefficient firm produces higher quantity than under full commitment and the tax revenue is lower. However, those contracts may not be incentive compatible if the discount factor and the second period price are high and thus the regulator may be forced to implement a pooling contract.

Keywords: Nonrenewable resources, commitment, asymmetric information JEL Classification: Q38, D82

\section{Introduction}

Despite the reinforcement of state permanent sovereignty over natural resources by the United Nation Charter in 1962, governments in developing countries may not have the technical skills (seismic surveys, drilling wells, extraction techniques) nor the financial means (low access to capital markets) to efficiently exploit their natural resources. Hence, governments often delegate the exploration and extraction activities to international oil companies. Indeed, Eller et al. (2007) using a composite index to study the efficiency in generating revenue from inputs of employees and oil reserves show that international companies are more efficient than national oil companies. One of the main issues of delegating the petroleum activities is the asymmetric information problems that may arise. In fact, the government and the oil company do not have the same goals and thus as soon as one of them has private information, he has the incentive to use this information 
to the detriment of the other. The government seeks to promote exploration and extraction activities, maximize its fiscal revenue and acquire some knowledge. Whereas, the oil company wants a fair profit share, minimize the risks (political and technical) and recover its investment. For more on the resource owner and manager's objectives, one can refer to Johnston (1994). The oil company has more expertise to estimate the quality or the quantity of resources and has more information on the technology it uses to foster and extract the resource. As a consequence, it may have the incentive to conceal information in order to get a higher revenue. Furthermore, the strength of commitment that binds the oil company to the government plays a crucial role, especially in presence of asymmetric information, as weak commitment can lead to the ratchet effect. The non commitment reflects the limited duration of petroleum agreements and is usually related to the incomplete contract theory. In reality, we observe a lack of commitment from governments as they often renegotiate petroleum agreements especially when prices are high. For example, in the 1970s and early 1980s, the increase in price of oil led to contracts renegotiation and in some cases, nationalizations. More recently Russia and Venezuela have also renegotiated their petroleum agreements.

A considerable amount of literature has been published on principal-agent models without commitment and only few papers use the contract theory approach to study the natural resource management.

The allocation under full commitment is not time consistent as in the second period, the inefficient firm and the regulator may benefit from a rene- 
gotiation. However, this ex post renegotiation changes ex ante incentives, as the quantity of the inefficient firm increases, the informational rent given to the efficient firm should increase as well. The non commitment literature such as Freixas et al. (1985), Laffont and Tirole (1988), Laffont and Tirole (1990) and Dionne and Fluet (2000) pointed out two important effects. In the settings where an economic agent (the principal) delegates the production to another economic agent without knowing the agent's type (efficient or inefficient in production activity), some pooling can be optimal and both types may have the incentive to lie. Indeed, under no commitment the principal can use the information learned in early periods to design future contracts (i.e ratchet effect). To induce separation, the principal has to leave the efficient type with a high informational rent in the first period. This rent should compensate the agent for revealing its information and jeopardizing any future informational rents. As the opportunity cost of revealing information increases with the discount factor, the informational rent does as well. When the discount factor is high, the efficient type may pool with an inefficient one to keep future informational rents. Separation becomes so costly that some pooling can be optimal. Moreover, as a consequence, the inefficient firm may adopt the "take-the-money-and-run" strategy, it chooses the efficient type's contract in the first period and then quits the relationship.

So far, the principal-agent model has rarely been used to study delegation contracts between the government and the oil company. One can cite two main attempts to introduce asymmetric information in delegation contracts for non renewable resource. Gaudet et al. (1995) and Osmundsen (1998) study in a two-period model the impact on the optimal contract of asym- 
metric information on the productive efficiency. Both consider only one firm (the agent) and one regulator (the principal) and no exploration. In the first paper, the efficiency changes at each period, the contract is a two-period contract but the firm can opt out in the second period if its efficiency is really low. Gaudet et al. (1995) mainly focus on the dynamics implied by the resource constraint and show that when it is optimal for all types of firms to exhaust the stock, the inefficient firms should produce lower quantity than the first best (symmetric information case) whereas the efficient firm should produce the first best (no distortion at the top). However, if it is not optimal for some types of firms to exhaust the stock in the second period, it may be optimal for the most efficient firm to produce more than the first best. Indeed, its second-period extraction may be lower than the first best if it is inefficient in the second period. Osmundsen (1998) assumes full commitment, an efficiency parameter correlated with the stock of resources (which is private information) and that it is never optimal to exhaust the stock. He mainly focuses on the impact of the stock effect on the optimal contracts and assumes that the efficiency decreases as the stock is depleted. He finds that at each period no distortion at the top is optimal and that the productive distortion of the inefficient firms should be higher in the first period as this extraction increases the second period costs. Two other papers study the effect of adverse selection on the firm's efficiency in the context of delegation contract of non renewable natural resource management. Osmundsen (1998) is the continuation of the static model developed in Osmundsen (1995) in which non neutral taxation such as a menu of linear tax contracts composed of a license fee and a royalty can be optimal. Moreover, Hung et al. (2006) 
show that, under asymmetric information the contract duration is longer than under symmetric information whereas the scarcity rent is lower. They also show that just before the end of the contract the firm may produce higher quantity than the first best. The main contribution of this paper is to relax the two-period assumptions.

The objective of our paper is to complement those works by introducing an informational dynamics. We study the concession contracts implemented if the government and the firm are unable to commit to long term contracts and if the firm has private information on its extraction costs. In addition, as in Hung et al. (2006), we consider firms with a constant efficiency parameter. We study an extreme case of ratchet effect given that if the information is revealed in the first period, there is symmetric information in the second one. We consider two types of firms, only two periods and a two contract menu. We use the same approach as Laffont and Tirole (1993) (chapter 9) but adapt it to a nonrenewable resource market as we add to the incentive and participation constraints a stock constraint. This model captures two types of dynamics; one from the exhaustibility and one from the ratchet effect. We study how the non commitment impacts the incentives, the tax revenue and the extraction path. Moreover, we study the impact of the discount factor and compare the extraction path to the one under symmetric information and asymmetric information and full commitment.

Because of the stock constraint, new effects appear compared to standard principal-agent models: 
First, as in a standard model, there is a trade off between rent extraction and productive efficiency. By decreasing the extraction requested from a less efficient firm, the principal is able to reduce the informational rent and thus increase its payoff. As the less efficient firm's extraction decreases, its contract becomes less attractive for an efficient firm and the informational rent is lower. However, as we consider a nonrenewable resource, if the stock is exhausted, this rent extraction efficiency trade off changes. By decreasing the less efficient firm's extraction in the first period in order to lower the informational rent left, the regulator automatically increases the second period extraction and thus the informational rent left at this period.

Then, when it is optimal for both types of firms to exhaust the stock, the cumulated extraction is the same for both types and this may lower the contract's incentive power. Indeed, an efficient firm may produce the same quantity whether it reveals or lies.

Finally, an increase in the discount factor has two effects, on the one hand it slows the extraction down (non renewable resource effect) and on the other hand, it decreases the incentive to the firm to jeopardize future informational rent (adverse selection effect).

The paper is organized as follows. Section 2 presents the general settings and the assumptions. Section 3 characterizes the benchmarks: the optimal contracts under symmetric information and under asymmetric information and full commitment. In section 4, we compute the allocation under non commitment, and find that the contracts implemented depend on which types of firms exhaust the stock. The contracts might be the same as under full com- 
mitment or semi separating contracts such that the inefficient firm produces higher quantity than under full commitment. The latter contracts induces a lower tax revenue and may not be incentive compatible if the discount factor and the second period price are high. We end this paper with the conclusion in section 5 .

\section{General settings}

As in Gaudet et al. (1995) and Osmundsen (1998), we consider two periods $t=\{1,2\}$ and no competition within the regulators and the firms (only one resource owner and one firm interact). As in the previous models, we assume that the exploration has been completed and there is no fixed cost. The firm's cost function is the same as Gaudet et al. (1995) with a constant efficiency parameter $\theta$.

$$
C\left(\theta, q_{t}\right)=\theta q_{t}+\frac{b}{2} q_{t}^{2}
$$

The regulator knows $b>0$ and is able to verify the quantity extracted $q_{t}$ and the price of the resource $p_{t}$ but does not know $\theta$ and has prior belief on the probability to face one type of firms. With probability $\nu_{0}$ the regulator faces an efficient firm $\underline{\theta}$ and with the complementary probability, he faces a inefficient firm $\bar{\theta}$ where $\underline{\theta}<\bar{\theta}$ and $\bar{\theta}<p_{t}$. We denote: $\Delta \theta=\bar{\theta}-\underline{\theta}$ and $\delta \in[0,1]$ the discount factor.

The regulator designs a contract that specifies the quantity $q_{t}$ that should be extracted and the transfer $t_{t}$ he will receive at each period $t$. The firm gets all the profit from the extraction and pays a transfer at each period to 
the regulator. The regulator's payoff is the discounted sum of transfer. As oil companies are often multinational, the regulator only cares about the tax revenue generated from the extraction and does not consider the firm's profit in his payoff function. The firm only has a secondary role as the quantity is imposed by the regulator and the firm only decides if it participates and under which contract. We denote $U_{R}$ and $U_{F}$ respectively the regulator and the firm's payoff.

$$
\begin{gathered}
U_{R}=t_{1}+\delta t_{2} \\
U_{F}=p_{1} q_{1}-C\left(\theta, q_{1}\right)-t_{1}+\delta\left[p_{2} q_{2}-C\left(\theta, q_{2}\right)-t_{2}\right]
\end{gathered}
$$

The regulator maximizes its payoff subject to the firm's participation and a stock constraint which states that the quantity extracted cannot exceed the initial stock of resource $S$. We normalize the outside opportunity of the firm to zero and if there is asymmetric information, we add incentive constraints. The first period affects the second period, as the stock of resource available in the second period decreases with the first period extraction. One solve this problem using backward induction.

We use the following subscripts: (FB) for symmetric information, (FC) for asymmetric information and full commitment, (NC) for asymmetric information and non commitment. 


\section{Benchmark}

\subsection{Symmetric information}

If we assume risk neutral agents, only the aggregate transfer matters and the firm is indifferent between paying $t_{t}$ at each period or $T=t_{1}+\delta t_{2}$ as an upfront payment. The regulator maximize its payoff (11) subject to the firm's participation (2) and a stock constraint (3). Solving this problem, one can define the first best's contracts.

$$
\max _{\left\{T, q_{1}, q_{2}\right\}} U_{R}=T
$$

subject to

$$
\begin{array}{r}
U_{F}=p_{1} q_{1}-C\left(\theta, q_{1}\right)+\delta\left[p_{2} q_{2}-C\left(\theta, q_{2}\right)\right]-T \geq 0 \\
q_{1}+q_{2} \leq S
\end{array}
$$

The constraint (2) binds, the regulator gets all the profits. Introducing (2) in (1):

$$
\max _{\left\{q_{1}, q_{2}\right\}} U_{R}=T=p_{1} q_{1}-C\left(\theta, q_{1}\right)+\delta\left[p_{2} q_{2}-C\left(\theta, q_{2}\right)\right] \text { subject to (3) }
$$

The extraction depends on $S, p_{1}, p_{2}, b$ and $\theta$. There are 6 solutions $(0, S)$, $(S, 0),\left(q_{1 N E}, 0\right), \quad\left(0, q_{2 N E}\right),\left(q_{1 N E}, q_{2 N E}\right),\left(q_{1 E}, S-q_{1 E}\right)$. We focus on two solutions:

If $\theta_{a} \leq \theta \leq p_{t}$, (3) does not bind and the extraction is: $q_{t N E}^{F B}=\frac{p_{t}-\theta}{b}$ with $t=\{1,2\}$ 
If $\theta_{b} \leq \theta \leq \operatorname{Min}\left\{\theta_{c}, \theta_{a}\right\},(3)$ binds and the extraction is: $q_{1 E}^{F B}=\frac{p_{1}+\delta\left(b S-p_{2}\right)-(1-\delta) \theta}{b(1+\delta)}$ and $q_{2 E}^{F B}=S-q_{1 E}^{F B}$

The subscripts $N E$ and $E$ stands respectively for not exhausted and exhausted (in period 2) and $\theta_{a}=\frac{p_{2}+p_{1}-b S}{2}, \theta_{b}=\frac{p_{1}-\delta p_{2}-b S}{1-\delta}$ and $\theta_{c}=\frac{p_{1}-\delta p_{2}+\delta b S}{1-\delta}$

Lemma 1 The stock is exhausted if the price is high in both periods, the firm efficient and the stock is relatively low. Moreover, the firm spreads the extraction if the price path is smooth and the stock high enough. The first period extraction depends on whether the remaining stock is exhausted at the second period.

The efficiency increases the extraction except in the second period if the stock is exhausted. If $\delta=1$, the extraction is independent from the efficiency, the firms produce the same quantity. If the stock is exhausted, the extraction follows a standard Hotelling rule, the higher the discount factor is, the less intensive the extraction is. If the price is constant over time, the extraction path is decreasing.

\subsection{Asymmetric information and full commitment}

We denote $\underline{U}$ and $\bar{U}$ respectively, the efficient and the inefficient firm's payoff and $\left(\underline{q}_{1}, \underline{q}_{2}, \bar{T}\right)$ and $\left(\bar{q}_{1}, \bar{q}_{2}, \underline{T}\right)$ their respective contracts. If the regulator does not know the firm's efficiency, the first best contracts cannot be used as the firm lies when the contract designed for the other type gives a positive payoff. The firm may lie (L) or reveal (R) its type. 
$\underline{U}_{L}=\Delta \theta\left(\bar{q}_{1}^{F B}+\delta \bar{q}_{2}^{F B}\right) \geq 0$ and $\bar{U}_{L}=-\Delta \theta\left(\underline{q}_{1}^{F B}+\delta \underline{q}_{2}^{F B}\right) \leq 0$

The efficient firm has the incentive to undervalue its efficiency to receives the cost differential. The inefficient firm has never the incentive to lie as this implies a high extraction compared to its efficiency (there is no countervailing incentives). Thus, in case of asymmetric information we have to define another type of contracts.

If the regulator can fully commit to long term contracts, he proposes in the first period a contract designed for each firm that specifies the transfer he receives and the quantity extracted at each period. The regulator maximizes his payoff subject to the firm's participation (6) and (7), incentive (8) and (9) and stock (11) and 10 constraints. This is a special case of Gaudet et al. (1995) where the efficiency is constant and with only two types. Therefore, the results are similar but are recalled as they are used as a benchmark.

$$
\max _{\left\{\underline{q}_{1}, \underline{q}_{2}, \underline{T}\right\},\left\{\bar{q}_{1}, \bar{q}_{2}, \bar{T}\right\}} U_{R}^{F C}=\nu_{0} \underline{T}+\left(1-\nu_{0}\right) \bar{T}
$$

subject to

$$
\begin{array}{r}
\underline{U}\left(\underline{q}_{1}, \underline{q}_{2}, \underline{T}\right) \geq 0 \\
\bar{U}\left(\bar{q}_{1}, \bar{q}_{2}, \bar{T}\right) \geq 0 \\
\underline{U}\left(\underline{q}_{1}, \underline{q}_{2}, \underline{T}\right) \geq \underline{U}\left(\bar{q}_{1}, \bar{q}_{2}, \bar{T}\right) \\
\bar{U}\left(\bar{q}_{1}, \bar{q}_{2}, \bar{T}\right) \geq \bar{U}\left(\underline{q}_{1}, \underline{q}_{2}, \underline{T}\right) \\
\underline{q}_{1}+\underline{q}_{2} \leq S \\
\bar{q}_{1}+\bar{q}_{2} \leq S
\end{array}
$$

The constraints (8) and (7) imply (6). This is a standard problem where we 
should consider (7) and (8) binding. We check ex post if the non binding constraints are satisfied at the equilibrium.

The efficient firm extracts the first best quantity in both periods.

The inefficient firm produces lower quantity than the first best and there are still 6 solutions depending on $S, p_{1}, p_{2}, b, \bar{\theta}, \underline{\theta}$ and $\nu_{0}$. We focus on two solutions:

If $\theta_{a}\left(1-\nu_{0}\right)+\nu_{0} \underline{\theta} \leq \bar{\theta} \leq p_{t}\left(1-\nu_{0}\right)+\nu_{0} \underline{\theta}$, 11) does not bind and it is optimal to extract at each period: $\bar{q}_{t}^{F C}=\bar{q}_{t N E}^{F B}-\frac{\Delta \theta \nu_{0}}{b\left(1-\nu_{0}\right)}$

If $\theta_{b}\left(1-\nu_{0}\right)+\nu_{0} \underline{\theta} \leq \theta \leq \operatorname{Min}\left\{\theta_{c}\left(1-\nu_{0}\right)+\nu_{0} \underline{\theta}, \theta_{a}\left(1-\nu_{0}\right)+\nu_{0} \underline{\theta}\right\}$, 11 binds and it is optimal to extract $\bar{q}_{1 E}^{F C}=\bar{q}_{1 E}^{F B}-\frac{\Delta \theta \nu_{0}(1-\delta)}{b\left(1-\nu_{0}\right)(1+\delta)}$ and $q_{2 E}^{F C}=S-q_{1 E}^{F C}$

Lemma 2 Compared to symmetric information, the inefficient firm's extraction is lower. The firm may not exhaust the stock or extract the resource whereas under symmetric information it would have been optimal. Because of the rent efficiency trade off, the size of asymmetric information $(\Delta \theta)$ and the probability to face an efficient firm $\left(\nu_{0}\right)$ decrease the inefficient firm's extraction. This is a special case of Gaudet et al. (1995).

When the stock is exhausted, the discount factor decreases the distortion in the first period but still decreases the inefficient firm's first period extraction, this is consistent with the Hotelling rule. If $\delta=1$, then both firm produce the same quantity (the first best) and the efficient firm gets a really high informational rent. Under full commitment, the optimal static contracts are used, there is no distortion at the top and the inefficient firm extracts 
lower quantity than the first best. Because of the informational rent, the regulator's payoff is lower than under symmetric information. The discount factor has no effect on the contracts implemented except through the stock constraint if the stock is exhausted.

One can show that the non binding constraints $(9)$ and $(6)$ are satisfied: $\underline{U}_{R}=\underline{U}_{L}=\Delta \theta\left(\bar{q}_{1}^{F C}+\delta \bar{q}_{2}^{F C}\right) \Leftrightarrow(6)$ is always satisfied.

$\bar{U}_{R}=0$ and $\bar{U}_{L}=-\Delta \theta\left[\underline{q}_{1}^{F C}-\bar{q}_{1}^{F C}+\delta\left(\underline{q}_{2}^{F C}-\bar{q}_{2}^{F C}\right)\right] \Leftrightarrow(9)$ is always satisfied as the efficient firm always produces at least as much as the inefficient one.

\section{Asymmetric information and non commit- ment}

Under non commitment, the regulator proposes at each period a contract designed for each type. We denote $\left(\underline{t}_{t}, \underline{q}_{t}\right)$ and $\left(\bar{t}_{t}, \bar{q}_{t}\right)$ the contracts designed for the efficient and inefficient type at period $t=\{1,2\}$. The second period contracts are designed after the regulator observed the contract chosen in the first period. The regulator updates its prior belief $\left(\nu_{0}\right)$ according to a Bayesian rule and the posterior belief $\nu_{1}$ are such that:

$$
\underline{\nu}_{1}=\frac{x \nu_{0}}{x \nu_{0}+y\left(1-\nu_{0}\right)} \quad \text { and } \quad \bar{\nu}_{1}=\frac{(1-x) \nu_{0}}{(1-x) \nu_{0}+(1-y)\left(1-\nu_{0}\right)} \quad \text { with } x+y>0
$$

$\underline{\nu}_{1}$ is the probability that the firm is efficient knowing that it chooses $\left\{\underline{q}_{1}, \underline{t}_{1}\right\}$ $\bar{\nu}_{1}$ is the probability that the firm is efficient knowing that it chooses $\left\{\bar{q}_{1}, \bar{t}_{1}\right\}$ $x$ is the probability that the efficient firm chooses $\left\{\underline{q}_{1}, \underline{t}_{1}\right\}$ in the first period. $y$ is the probability that the inefficient firm chooses $\left\{\underline{q}_{1}, \underline{t}_{1}\right\}$ in the first period. 
The type of equilibrium depends on the $x$ and $y$ values:

- A fully separating equilibrium occurs in the first period when $(x=$ $1, y=0)$ or $(x=0, y=1)$. Updating is perfect and the regulator is able to fully identify the type of firms he faces. In the second period, there is symmetric information

- A semi-separating equilibrium occurs in the first period when one type of firms plays a pure strategy while the other plays a mixed strategy. In the second period, the regulator imperfectly updates his belief.

- A pooling equilibrium occurs in the first period when both types choose the same strategy $(x=y=1)$ or $(x=y=0)$. In the second period, no updating is possible and $\nu_{0}=\nu_{1}$.

Steps of the game:

- Depending on its prior belief $\nu_{0}$, the regulator proposes one contract for each type $\left(\underline{t}_{1}, \underline{q}_{1}\right)$ and $\left(\bar{t}_{1}, \bar{q}_{1}\right)$.

- The firm chooses one contract and the regulator updates his belief (he may have full information) depending on the contract chosen.

- Depending on his updated belief $\nu_{1}$, the regulator proposes one contract for each type $\left(\underline{t}_{2}, \underline{q}_{2}\right)$ and $\left(\bar{t}_{2}, \bar{q}_{2}\right)$ or the first best contract if he knows the firm's type.

The firm chooses its strategy (reveal or lie) in the first period taking into account that revealing its type may jeopardize future informational rents. 
The higher the opportunity cost of revealing is, the less it reveals. To design the four contracts, the regulator has to consider this opportunity cost. We solve this problem using backward induction. First, we define the secondperiod optimal contracts that maximize the regulator's second period payoff (for a given stock and updated beliefs). Then, we derive the first-period optimal contracts knowing that in the second period, the optimal contracts are implemented.

Second-period contracts

The second period problem is the same as the static one except that the prior beliefs are replaced by the revised ones $\left(\nu_{1}\right)$. The regulator maximizes his payoff for a given stock, subject to the firm participation (13) and (14), incentive (15) and (16) and stock constraints (18) and (17):

$$
\max _{\left\{\underline{q}_{2}, t_{2}\right\},\left\{\bar{q}_{2}, \bar{t}_{2}\right\}} U_{G_{2}}=\nu_{1} \underline{t}_{2}+\left(1-\nu_{1}\right) \bar{t}_{2}
$$

subject to

$$
\begin{array}{r}
p_{2} \underline{q}_{2}-C\left(\underline{\theta}, \underline{q}_{2}\right)-\underline{t}_{2} \geq 0 \\
p_{2} \bar{q}_{2}-C\left(\bar{\theta}, \bar{q}_{2}\right)-\bar{t}_{2} \geq 0 \\
p_{2} \underline{q}_{2}-C\left(\underline{\theta}, \underline{q}_{2}\right)-\underline{t}_{2} \geq p_{2} \bar{q}_{2}-C\left(\underline{\theta}, \bar{q}_{2}\right)-\bar{t}_{2} \\
p_{2} \bar{q}_{2}-C\left(\bar{\theta}, \bar{q}_{2}\right)-\bar{t}_{2} \geq p_{2} \underline{q}_{2}-C\left(\bar{\theta}, \underline{q}_{2}\right)-\underline{t}_{2} \\
\bar{q}_{1}+q_{2}\left(\bar{\nu}_{1}\right) \leq S \\
\underline{q}_{1}+q_{2}\left(\underline{\nu}_{1}\right) \leq S
\end{array}
$$


This is a standard problem where we should consider 14 and 15 binding. The problem is exactly the same as the full commitment one except that $\nu_{0}$ is replaced by $\nu_{1}$. Indeed, under full commitment the allocation is the same as the repetition of the optimal static contracts at each period. The efficient firm extracts the first best as under the full commitment and the inefficient firm's extraction is exactly the same as under full commitment except that $\nu_{0}$ is replaced by $\nu_{1}$.

One can show that the non binding participation $(13)$ and incentive $(16)$ constraints are satisfied:

$\underline{U}_{2 L}=\underline{U}_{2 R}=\Delta \theta \bar{q}_{2}^{N C}\left(\nu_{1}\right) \Leftrightarrow 13$ is always satisfied.

$\bar{U}_{2 R}=0$ and $\left.\bar{U}_{2 L}=-\Delta \theta\left(\underline{q}_{2}^{N C}\left(\nu_{1}\right)-\bar{q}_{2}^{N C}\left(\nu_{1}\right)\right)<0 \Leftrightarrow 16\right)$ is always satisfied as the efficient firm always produces at least as much as the inefficient one.

$\nu_{1}$ can be equal to $\bar{\nu}_{1}$ or $\underline{\nu}_{1}$ depending on which contract has been chosen in the first period. The second period non commitment scheme is similar to the full commitment one except that, beliefs have been revised according to the firm's strategy in the first period. The trade off between rent extraction and efficiency favours efficiency when $\nu_{1}$ is low and the rent extraction when $\nu_{1}$ is high. If $\nu_{0}>\nu_{1}$, for a given price path and a given stock, compared to the full commitment scheme, the quantity extracted by the inefficient firm is more intensive. Because the regulator is less confident about facing an efficient firm he is less willing to distort the quantity extracted by the inefficient firm to reduce the efficient firm's rent. If the posterior beliefs are such that $\nu_{0}<\nu_{1}$, the extraction of the inefficient firm is less intensive than under full 
commitment.

If the regulator does not know at the end of the first period the type of firms he faces, the efficient firm gets an informational rent.

If the regulator knows at the end of the first period the type of firms he faces, in the second period, only one contract is proposed (the symmetric information one). If $\nu_{1}=1$, the contract proposed is $\left\{\underline{q}_{2}^{F B}, \underline{t}_{2}^{F B}\right\}$ and if $\nu_{1}=0$, the contract proposed is $\left\{\bar{q}_{2}^{F B}, \bar{t}_{2}^{F B}\right\}$. Compared to under full commitment, the regulator is able to correct the inefficient firm's productive distortion and the efficient firm does not receive a rent.

\section{First-period contracts}

The firm knows its first period strategy affects the second period contracts through the updated belief and the stock and thus uses global incentive and participation constraints. These constraints take into account that in the second period, the inefficient firm never gets a rent and does not have the incentive to lie. Therefore, its participation and incentive constraints are only composed by the first-period payoff. Furthermore, as the efficient firm is indifferent between lying and telling the truth it gets an informational rent: $\Delta \theta \bar{q}_{2}\left(\nu_{1}\right)$. The incentive and participation global constraints used to solve 
the regulator problem are:

$$
\begin{array}{r}
p_{1} \underline{q}_{1}-C\left(\underline{\theta}, \underline{q}_{1}\right)-\underline{t}_{1}+\delta \Delta \theta \bar{q}_{2}\left(\underline{\nu}_{1}\right) \geq 0 \\
p_{1} \bar{q}_{1}-C\left(\bar{\theta}, \bar{q}_{1}\right)-\bar{t}_{1} \geq 0 \\
p_{1} \underline{q}_{1}-C\left(\underline{\theta}, \underline{q}_{1}\right)-\underline{t}_{1}+\delta \Delta \theta \bar{q}_{2}\left(\underline{\nu}_{1}\right) \geq p_{1} \bar{q}_{1}-C\left(\underline{\theta}, \bar{q}_{1}\right)-\bar{t}_{1}+\delta \Delta \theta \bar{q}_{2}\left(\bar{\nu}_{1}\right) \\
p_{1} \bar{q}_{1}-C\left(\bar{\theta}, \bar{q}_{1}\right)-\bar{t}_{1} \geq p_{1} \underline{q}_{1}-C\left(\bar{\theta}, \underline{q}_{1}\right)-\underline{t}_{1}
\end{array}
$$

Depending on the binding constraints different equilibria occur. In each case (20) binds; if not, one could always increase the tax revenue and keep the other constraints satisfied. Furthermore, (19) is implied by (20) and (21). Hence three cases may occur: only the efficient firm's incentive constraint binds (standard case), only the inefficient firm's incentive constraint binds (case II) and both incentive constraints bind (case III). One can show that case II, is only incentive compatible when both types produce the same quantity (when this contract is similar to a full pooling contract). Furthermore, we did not report case III as the extraction path and the results mainly depends on the $x$ and $y$ relative values.

\section{Standard contract}

In this case (20) and (21) bind. The efficient firm is indifferent between lying and telling and may randomize its action (reveal or lie). We consider that the inefficient firm reveals $(y=0)$ and we check ex post under which conditions its incentive constraint is satisfied. In the first period, if the contract $\left\{\underline{q}_{1}, \underline{t}_{1}\right\}$ is chosen, there is symmetric information, the regulator proposes in the second period only the efficient firm's first best contract $\left(\underline{\nu}_{1}=\right.$ 
$1)$. If the contract $\left\{\underline{q}_{1}, \underline{t}_{1}\right\}$ is chosen, the regulator still faces an asymmetric information problem but revises his belief according to the strategy observed:

$$
\bar{\nu}_{1}=\frac{(1-x) \nu_{0}}{(1-x) \nu_{0}+\left(1-\nu_{0}\right)} \leq \nu_{0}
$$

Lemma 3 As $\bar{\nu}_{1}<\nu_{0}$, the second period extraction of an inefficient firm is higher than under full commitment. Furthermore, as $\bar{\nu}_{1}$ decreases with $x$, an increase in $x$ increases the inefficient firm's second period extraction.

Depending on the value of $x$, different equilibria occur. For $x=1$, the first period contracts are fully separating and the inefficient firm extracts the same as under full commitment. In the second period, there is symmetric information and the first best contracts are proposed. For $x=0$, the efficient firm pools with an inefficient firm. In the second period, the contracts are the same as under full commitment. For $x \in] 0,1$, semi separating contracts are implemented.

When $\left\{\underline{q}_{1}, \underline{t}_{1}\right\}$ is chosen, there is full information in the second period. Only the efficient firm's first best contract is proposed and thus the firm has no information rent in the second period. The incentive and participation constraints of the efficient firm (19) and (21) can be rewritten:

$$
\begin{array}{r}
p_{1} \underline{q}_{1}-C\left(\underline{q}_{1}, \underline{\theta}\right)-\underline{t}_{1} \geq 0 \\
p_{1} \underline{q}_{1}-C\left(\underline{q}_{1}, \underline{\theta}\right)-\underline{t}_{1} \geq p_{1} \bar{q}_{1}-C\left(\bar{q}_{1}, \underline{\theta}\right)-\bar{t}_{1}+\delta \Delta \theta \bar{q}_{2}\left(\bar{\nu}_{1}\right)
\end{array}
$$


The regulator's payoff is the weighted sum of the possible transfers he might get:

$$
\begin{array}{r}
\max _{\left\{\underline{q}_{1}, \underline{t}_{1}\right\},\left\{\bar{q}_{1}, \bar{t}_{1}\right\}} U_{G}^{N C}=\nu_{0}\left(x \underline{t}_{1}+(1-x) \bar{t}_{1}\right)+\left(1-\nu_{0}\right) \bar{t}_{1} \\
+\delta\left\{\nu_{0} x \underline{t}_{2}^{F B}+\left(\nu_{0}(1-x)+\left(1-\nu_{0}\right)\right)\left[\bar{\nu}_{1} \underline{t}_{2}+\left(1-\bar{\nu}_{1}\right) \bar{t}_{2}\right]\right\}
\end{array}
$$

subject to (23) (20) (24) (22) (27) 28) with

$$
\begin{aligned}
& \underline{q}_{1}+\underline{q}_{2}\left(\underline{\nu}_{1}\right) \leq S \\
& \bar{q}_{1}+\bar{q}_{2}\left(\bar{\nu}_{1}\right) \leq S \\
& \bar{q}_{1}+\underline{q}_{2}\left(\bar{\nu}_{1}\right) \leq S
\end{aligned}
$$

The first part of the payoff is the transfer the regulator gets when the firm is efficient (it may lie or tell the truth). The second part is the transfer when the firm is inefficient (the regulator gets all the rent). The last part is the second period transfer, full information if the firm is efficient and tells the truth and asymmetric information if the firm is inefficient or if it is efficient and lies.

Solving this problem, one can show that:

The efficient firm extracts the first best level and thus the same as under full commitment. Whether it lies or reveals it gets a payoff equal to $\Delta \theta\left(\bar{q}_{1}^{N C}+\delta \bar{q}_{2}^{N C}\right)$. If it reveals, this payment is given in the first period.

The optimal extraction of an inefficient firm depends on $S, p_{1}, p_{2}, b, \bar{\theta}$, $\underline{\theta}, \nu_{0}$ and $x$. There are several solution depending on which stock constraints bind and we focus on three cases: in the second period, (i) none of the stock 
constraint or only (26) bind, (ii) 26 and (28) bind, (iii) all the the stock constraints bind.

i) If $\theta_{d} \leq \bar{\theta} \leq p_{1}\left(1-\nu_{0} x\right)+\nu_{0} x \underline{\theta}$, none of the firms exhaust the resource or only an efficient firm that reveals its type. It is optimal to extract in the first period:

$$
\bar{q}_{1 N E}^{N C}=\bar{q}_{1 N E}^{F B}-\frac{\Delta \theta \nu_{0} x}{b\left(1-\nu_{0} x\right)}
$$

ii) If $\operatorname{Max}\left\{\theta_{e}, \theta_{f}\right\} \leq \bar{\theta} \leq \operatorname{Max}\left\{\theta_{d}, \theta_{g}\right\}$, only the efficient firm exhausts the stock (whatever its strategy in the first period is). It is optimal to extract in the first period:

$$
\bar{q}_{1 \underline{E}}^{N C}=\bar{q}_{1 N E}^{F B}-\frac{\nu_{0}[\Delta \theta(x-\delta(1-x))-\delta(1-x) Z(\underline{\theta})]}{b\left(1-\nu_{0} x+\delta \nu_{0}(1-x)\right)}
$$

with $Z(\underline{\theta})=2 \underline{\theta}+b S-p_{2}-p_{1}$

$\theta_{d}=\left(1-\nu_{0} x\right)\left(p_{1}-p_{2}-b S\right)+\underline{\theta}\left(2 \nu_{0} x-1\right)$

$\theta_{e}=\underline{\theta} \nu_{0} x+\left(\delta\left(\underline{\theta}-p_{2}\right)-b S+p_{1}\right) \nu_{0}(1-x)+\left(p_{1}-b S\right)\left(1-\nu_{0}\right)$

$\theta_{f}=\frac{\theta \nu_{0}\left((1+\delta)\left(\nu_{0} x(x-1)+1\right)-\left(\nu_{0}+\delta\right) x\right)}{\left(1-\nu_{0} x\right)\left(1+\delta \nu_{0}-(1+\delta) \nu_{0} x\right)+1-\nu_{0}}-\frac{\left(b S-p_{2}-p_{1}\right)\left(1-\nu_{0}\right)\left(1-\nu_{0} x\right)}{\left(1-\nu_{0} x\right)\left(1+\delta \nu_{0}-(1+\delta) \nu_{0} x\right)+1-\nu_{0}}$

$\theta_{g}=\underline{\theta} \nu_{0} x+\left(\delta\left(\underline{\theta}+b S-p_{2}\right)+p_{1}\right) \nu_{0}(1-x)+p_{1}\left(1-\nu_{0}\right)$

iii) If $\theta_{b}\left(1-\nu_{0} x\right)+\nu_{0} x \underline{\theta} \leq \bar{\theta} \leq \operatorname{Min}\left\{\theta_{c}\left(1-\nu_{0} x\right)+\nu_{0} x \underline{\theta}, \theta_{a} \frac{2\left(1-\nu_{0}\right)\left(1-\nu_{0} x\right)}{\left(1-\nu_{0} x\right)^{2}+1-\nu_{0}}+\underline{\theta} \frac{\nu_{0}\left(1-\nu_{0} x(2-x)\right)}{\left(1-\nu_{0} x\right)^{2}+1-\nu_{0}}\right\}$

(26), all firms exhaust the stock. It is optimal to extract in the first period:

$\widetilde{\bar{q}}_{1 E}^{N C}=\widetilde{\bar{q}}_{1 E}^{F B}-\frac{\Delta \theta \nu_{0} x(1-\delta)}{b(1+\delta)\left(1-\nu_{0} x\right)}$

Lemma 4 The size of the first period distortion depends on which stock constraint bind. As under commitment, the distortion depends on whether the inefficient firm exhausts the stock. But under non commitment, it also 
depends on whether the efficient firm exhausts the remaining stock when it lies in the first period.

If the efficient firm exhausts the remaining stock when it lies, it decreases the quantity extracted by an inefficient firm in the first period. The trade off between extracting in the first and second period appears even through the inefficient firm does not exhaust the stock. In the first period, the inefficient firm extraction lies between the first best and the full commitment ones. The first period extraction is thus closer to the first best. If the stock is exhausted, the second period extraction is higher than under the first best and lower than under full commitment. As the inefficient firm's extraction is higher than under full commitment, the informational rent left to the efficient firm is also higher. One can show that the regulator's payoff is lower under non commitment than under full commitment.

Proposition 1 Under non commitment, the efficient firm's extraction is the first best and the inefficient firm extracts at least as much as under full commitment (except in the second period when it is optimal to exhaust the stock). The extraction and the informational rent are higher than under full commitment and the regulator's payoff is at most equal to the full commitment one.

The discount factor has two effects on the inefficient firm's extraction. On the one hand, the regulator is more willing to postpone the extraction and thus decrease the first period extraction (resource effect). On the other hand, the efficient firm has less incentive to reveal as its rent is $\Delta \theta\left(\bar{q}_{1}^{F C}+\delta \bar{q}_{2}^{F C}\right)$. To mitigate this effect, the regulator may have the incentive to decrease the 
inefficient firm's second period extraction (adverse selection effect). If the stock is exhausted by the inefficient firm, an increase in the discount factor may intensify the extraction path.

If the inefficient firm never exhausts the stock (ii), the first period extraction has no impact on the informational rent associated with the second period. The only effect of the discount factor is to decrease the first period extraction. This is a standard Hotelling effect, the higher the discount factor is, the less intensive the extraction is. If all types of firms exhaust the stock (iii), both effects appear and an increase in the discount factor may intensify the extraction.

Proposition 2 Under non commitment, if the exogenous parameters are such that it is optimal for both firms to exhaust the stock, contrary to the Hotelling rule, an increase in the discount factor may intensify the extraction path as the weight of the informational rent increases.

We now study the effect of $x$ on the regulator's payoff. This allows us to determine whether, the regulator proposes full pooling contracts, semi separating contracts or fully separating contracts. Indeed, the optimal contracts are obtained by the probability $x$ which maximizes the regulator's payoff.

In the three cases, when the efficient firm is more likely to reveal, the inefficient firm's extraction is set to a lower level in order to decrease the informational rent. When $x=0$, the regulator's payoff strictly increases with $x$. Thus, it is never optimal to propose a full pooling contract (if the non binding incentive and participation constraints are satisfied for $x>0$ ) 
When both types exhaust the stock and a corner solution occurs in the first period, the regulator's payoff strictly increases with $x$ as the firm's informational rent strictly decreases with $x$. Thus, the regulator proposes fully separating contracts. In the second period, the regulator perfectly updates his beliefs, both firms produce the first best quantity. As the stock is exhausted, the extraction level does not depend on the level of information. The extraction is the same under full and non commitment and thus there is no cost of separating the firm in the first period. Because, the regulator proposes fully separating contracts and as the stock is exhausted, the regulator's payoff under full and non commitment is exactly the same.

Proposition 3 If the exogenous parameters are such that the non binding participation and incentive constraints are satisfied and the stock is exhausted by both types, the regulator is always better off when the firm reveals and thus proposes fully separating contracts. Whatever the type of commitment is, asymmetric information has the same effect on the contracts and extraction levels.

In the two other cases, the regulator proposes fully separating contracts only if the discount factor is below some threshold, if not semi separating contracts are implemented as full separation becomes too costly.

Under fully separating contracts, the regulator's payoff is lower than under full commitment. Indeed, even if the first period extraction is the same, in the second period as the inefficient firm extracts the first best, the informational rent left to the efficient one is too high.

Under a semi separating contract, the inefficient firm extracts at each period higher quantity than under full commitment. An increase in $x$ lowers 
the first period extraction and increases the second period one.

Proposition 4 If the exogenous parameters are such that the non binding participation and incentive constraints are satisfied, none of the types exhausts the stock and the discount factor is below some threshold, fully separating contracts are implemented. If the discount factor is above the threshold, the efficient firm has to be highly compensated to reveal its information and semi separating contracts are implemented. Implementing a full pooling contract is never optimal.

If the stock is exhausted, when the discount factor increases, the regulator's payoff under non commitment moves closer to the full commitment one. If not, the regulator's payoff under non commitment moves away from the full commitment one.

We now have to check if the non binding constraints: the inefficient firm's incentives 22 and the efficient firm's participation 23 constraints are satisfied at the equilibrium for every couples $\left(\underline{q}_{1}^{N C}, \underline{q}_{2}^{N C}, \underline{t}_{1}^{N C}, \underline{t}_{2}^{N C}\right),\left(\bar{q}_{1}^{N C}, \bar{q}_{2}^{N C}, \bar{t}_{1}^{N C}, \bar{t}_{2}^{N C}\right)$. For simplicity's sake, we did not report all the corner solutions however, there exist several equilibria depending on the market conditions. For example, if $p_{1}$ is high, the contracts can be such that the efficient firm exhausts the stock in the first period whereas the inefficient firm spreads the extraction over time. For a very high $p_{2}$ it might be optimal for both firms to exhaust the stock in the second period and be inactive in the first.

$\underline{U}(L)=\underline{U}(R)=\Delta \theta\left(\bar{q}_{1}^{N C}+\delta \bar{q}_{2}^{N C}\right) \quad 23$ is always satisfied 
$\bar{U}(L)=\Delta \theta\left(\bar{q}_{1}^{N C}+\delta \bar{q}_{2}^{N C}-\underline{q}_{1}^{N C}\right) \quad 22$ is only satisfied if $\underline{q}_{1}^{N C} \geq \bar{q}_{1}^{N C}+\delta \bar{q}_{2}^{N C}\left(\bar{\nu}_{1}\right)$

The inefficient firm gets no rent in the first period when it reveals its type so it is attracted by the efficient firm's contract as soon as it gives a positive payoff. If the inefficient firm lies in the first period, it captures the informational rent: $\Delta \theta\left(\bar{q}_{1}^{N C}+\delta \bar{q}_{2}^{N C}\left(\bar{\nu}_{1}\right)\right)$ but suffers from a loss as it overextracts: $-\Delta \theta \underline{q}_{1}^{N C}$. We directly see that the higher the discount factor is, the harder it is to satisfy 22 .

In the second period, as the regulator is sure to face an efficient firm, only one contract $\left\{\underline{q}_{2}^{F B}, \underline{t}_{2}^{F B}\right\}$ is proposed. If the inefficient firm accepts this contract, it suffers from a loss: $\Delta \theta \underline{q}_{2}^{F B}$, so it leaves the relationship: this is the take-the-money-and-run strategy. The incentive constraint under non commitment is much harder to satisfy than under full commitment ${ }^{1}$

Under non commitment, the inefficient firm's incentive constraint is always satisfied when the inefficient firm is inactive in the second period or when the efficient firm extracts all the stock in the first period (the resource price is highly decreasing). The inefficient firm's incentive constraint is never satisfied when both firms are inactive in the first period (the resource price is highly increasing). Indeed, the efficient firm gets the informational rent without suffering from the first period overextraction.

\footnotetext{
${ }^{1}$ Under full commitment, (9) is satisfied if $\underline{q}_{1}^{F C}+\underline{q}_{2}^{F C}>\bar{q}_{1}^{F C}+\bar{q}_{2}^{F C}$
} 
22 is only satisfied for sufficiently low $p_{2}$ and $\delta$ and when the asymmetric information high enough $(\Delta \theta)$. If (22) is not satisfied then, both incentive constraints bind and both firms may randomize (case 3). This case highly depends on the value each firm lies and thus is not really interesting.

Proposition 5 When the second period price or the discount factor are high, the standard separating contracts are not incentive compatible. Indeed, because of the lack of commitment the efficient firm has to be highly compensated for its private information and thus, the contract becomes attractive for an inefficient firm.

As the standard contract is not always incentive compatible, the regulator has to use another contract when the market conditions are such that this contract cannot be implemented.

\section{The pooling contract}

The regulator only proposes one contract at each period: $\left\{q_{1}, t_{1}\right\},\left\{q_{2}, t_{2}\right\}$. As only one contract is proposed, there is no need for incentives constraints and only the participation constraints matter. The inefficient firm's participation constraint binds and the contracts are such that the firm extracts at each period, the inefficient firm first best quantity. If the firm is efficient it gets a positive rent: $\underline{U}=\Delta \theta\left(\bar{q}_{1}^{F B}+\delta \bar{q}_{2}^{F B}\right)$.

This pooling contract leads to decrease in the regulator's payoff compared to the standard separating contracts. This loss of revenue is increasing with $\Delta \theta$ and $\nu_{0}$ except for the extreme case $(0, S)$ which was not incentive compatible 
and where $U_{R}^{F C}=U_{R}^{N C}=U_{R}^{P}$

Proposition 6 A pooling contract can always be substituted to the standard separating contracts when they are not incentive compatible. The extraction is the same as under symmetric information if the firm is inefficient. This contract entails a distortion at the top as the efficient firm extracts lower quantity than the first best. The efficient firm gets a high informational rent and the inefficient one gets nothing. This contract lower the regulator's payoff compared when standard separating contracts are used.

\section{Conclusion}

If there is asymmetric information, the lack of commitment can be costly for the regulator as the information disclosed unable to correct for the inefficient firm's productive distortion and this increases the informational rent left to the efficient one. However, as the production of non renewable resources is limited, the problem changes.

If firms are efficient, the stock is relatively low and the price path is smooth, all types of firms exhaust the stock and spread the extraction over time. Having symmetric information comes without costs. Indeed, the production in the second period is the remaining stock of resources and thus is the same under symmetric and asymmetric information. As a consequence, the regulator always prefers to separate firms in the first period, and the lack of commitment has no effect on the firms and regulator's payoffs, only the asymmetric information has. Hence, having long term or short term contracts has no impact under asymmetric information as long as the stock of 
resource is exhausted by all types of firms. The contracts implemented are such that efficient firms produce the first best and get an informational rent whereas inefficient ones produce lower quantity.

Nevertheless, under non commitment, those contracts may not be incentive compatible. If the discount factor is high, inefficient firms may have the incentive to take the money and run as the informational rent left to the efficient firm is high and given as an upfront payment. In the first period, inefficient firms produce high quantity compared to their efficiency and pay a low payment to the government, in the second period they produce nothing as they leave the contract. To avoid this strategy, the regulator has to propose a pooling contract. Using a pooling contract implies that the government define a standard taxation scheme that applies for all firms whatever their efficiency are. In this case, efficient firms produce low quantity and get high informational rents whereas inefficient firms produce the same as under symmetric information.

In addition, if some firms are inefficient, the stock of resource is high and the price of resource is low, the stock may not be exhausted by all types of firms and the regulator might be better off with some amount of pooling. In this case, efficient firms produce the first best and get a relatively high informational rent whereas inefficient firms produce higher quantity than if the regulator is able to commit to long term contracts but lower quantity than the first best. Asymmetric information usually slows the extraction down but the lack of commitment decreases this effect, as the extraction is higher in both periods than under full commitment.

As an extension to this work, one should also study the case of renegotiation- 
proof contracts (the regulator and the firm sign a long term contract and are able to renegotiate the contract whenever it is mutually favourable). In case of renegotiation-proof contracts, the allocation usually lies between the non and full commitment.

\section{References}

Dionne, G. and Fluet, C. (2000). Full pooling in multi-period contracting with adverse selection and noncommitment. Review of Economic Design, $5(1): 1-21$.

Eller, S., Hartley, P., III, M., and Kenneth, B. (2007). Empirical evidence on the operational efficiency of national oil companies. The Changing Role of National Oil Companies in International Markets, part of a study at the James A. Baker Institute for Public Policy of Rice University.

Freixas, X., Guesnerie, R., and Tirole, J. (1985). Planning under incomplete information and the ratchet effect. Review of Economic Studies, 52(2):17391.

Gaudet, G., Lassere, P., and Long, N. V. (1995). Optimal resource royalties with unknown and temporally independent extraction cost structures. International Economic Review, 36(3):715-49.

Hung, N. M., Poudou, J.-C., and Thomas, L. (2006). Optimal resource extraction contract with adverse selection. Resources Policy, 31(2):78-85. 
Johnston, D. (1994). International Petroleum Fiscal Systems and Production Sharing Contracts. PennWell Publishing Company.

Laffont, J.-J. and Tirole, J. (1988). The dynamics of incentive contracts. Econometrica, 56(5):1153-75.

Laffont, J.-J. and Tirole, J. (1990). Adverse selection and renegotiation in procurement. Review of Economic Studies, 57(4):597-625.

Laffont, J.-J. and Tirole, J. (1993). A Theory of Incentives in Procurement and Regulation, volume 1 of MIT Press Books. The MIT Press.

Osmundsen, P. (1995). Taxation of petroleum companies possessing private information. Resource and Energy Economics, 17(4):357-377.

Osmundsen, P. (1998). Dynamic taxation of non-renewable natural resources under asymmetric information about reserves. Canadian Journal of Economics, 31(4):933-951. 